\title{
Can endoscopic therapy help surgeons to manage post-hepatectomy bile leaks?
}

\author{
Massimiliano Mutignani, Lorenzo Dioscoridi \\ Digestive Endoscopy Unit, ASST Niguarda, Milan, Italy \\ Correspondence to: Massimiliano Mutignani, MD. ASST Niguarda, Piazza dell'Ospedale Maggiore 3, 20162, Milan, Italy. \\ Email: massimiliano.mutignani@ospedaleniguarda.it. \\ Comment on: Spetzler VN, Schepers M, Pinnschmidt HO, et al. The incidence and severity of post-hepatectomy bile leaks is affected by surgical \\ indications, preoperative chemotherapy, and surgical procedures. Hepatobiliary Surg Nutr 2019;8:101-10.
}

Submitted Jan 18, 2021. Accepted for publication Mar 17, 2021.

doi: $10.21037 / \mathrm{hbsn}-2021-8$

View this article at: http://dx.doi.org/10.21037/hbsn-2021-8

We read with great interest the paper of Spetzler et al. on bile leaks after hepatectomy (1). The authors concluded that preoperative therapy and types of surgical procedures had the most significant influence both on incidence and severity of these adverse events.

Furthermore, the authors evidenced that grade $\mathrm{C}$ bile leaks (needing surgical retreatments) were associated with increased length of hospital-stay, infection rate and mortality.

Can endoscopic treatment help to improve these outcomes?

Firstly, we should remind that the output of the bile leak is not always related to the severity of the iatrogenic lesion: a high-grade output fistula $(>300 \mathrm{~mL} / \mathrm{die})$ can be related to a peripheral bile duct leak (i.e., cystic stump) associated with an overdistension of the biliary tree (i.e., due to a biliary stone impacted on the papilla).

Secondly, pathophysiological principles of bile leaks are the base of the endoscopic therapy.

With the biliary sphincter intact, intra-biliary pressure $(15-17 \mathrm{mmHg})$ is considerably higher than the intrabdominal pressure $(5-7 \mathrm{mmHg})$ and the enteral intraluminal pressure $(4-6 \mathrm{mmHg})$. If a bile leak is present and the biliary sphincter is intact, the pressure gradient (the intrabiliary-intrabdominal gradient on intrabiliary-enteral gradient) lets the bile to flow out from the biliary tree into the peritoneal cavity. The presence of an abdominal drain lowers the intrabdominal pressure at that level to the atmospheric pressure (conventionally considered as
0 value) (2). As a consequence of this pressure balance, the bile moves from the bile duct not only into the abdominal cavity but preferentially outside through the drain. To promote fistula healing, diversion of the bile flow from the bile duct into the duodenum should be obtained.

Spetzler et al. wrote that reoperation was performed in three situations; one of them was daily drainage output $>500 \mathrm{~mL}$ without decreasing potential despite endoscopic or radiological intervention. In this situation, the localization of the abdominal drainage must be considered as potential cause of failure (2). If the abdominal drain is next to the bile leak, even if biliary sphincterotomy is correctly performed, the bile may continue to go out from the biliary tree into the abdominal drain because the biliary-atmospheric pressure gradient is greater than biliary-duodenal one. Thus, the abdominal drain has to be retrieved $4-6 \mathrm{~cm}$ from the site of the bile leak, after biliary sphincterotomy (2).

Furthermore, Spetzler et al. wrote the most severe bile leaks (grade C) were observed after left hepatectomy or right extended hepatectomy. In these situations, the leak can derive from a main hepatic duct (i.e., left or right hepatic duct). Once again, the endoscopic treatment can avoid reoperation. To solve the leak, a large-bore fullycovered self-expandable biliary metal stent with the distal edge outside of the leaking stump, into the peritoneal cavity and the proximal edge into the duodenal lumen, can be placed transpapillary. This biliary stent will overpass the intrabdominal-intrabiliary pressure gradient and the intrabiliary-duodenal pressure gradient, bringing the bile 
directly from the abdominal cavity into the duodenal lumen. The position of the abdominal drainage must be checked as we explained before; additional biliary stents can be placed to avoid the obstruction of the remaining biliary tree after metal stenting. The stents can be removed 4-6 weeks after the procedure.

In case of leaks from bilio-digestive anastomoses (BDA), many authors recommended conservative treatment to avoid a worsening of the leak itself, as discussed by Spetzler. Endoscopy can help also in this adverse event.

In BDA leaks setting, it is important to distinguish two subtypes of biliary fistulas: (I) simple anastomotic dehiscence, without necrosis of the enteral wall around the anastomosis; (II) complex anastomotic dehiscence, with necrosis of the enteral wall around the anastomosis. In the first case, endoscopic therapy consists in biliary stenting alone (generally using fully covered metal stents). However, in the second subtype, biliary stenting is not sufficient because the biliary fistula is combined to an enteral leak. Thus, combined enteral and biliary stenting should be performed in tertiary referral centers (3) to close both the sources of fistula.

In the end, we should remind that few uncontrolled biliary leaks after liver resections can be caused by leaking bile duct transected and isolated from the remaining biliary tree during surgery (4).

Considering the pathophysiology, it is possible to change endoscopically the pressure gradient of the fistula in order to direct bile flow from the isolated duct towards the duodenal lumen, thus creating an internal biliary fistula to restore bile flow. The key element of endoscopic treatment in this case is to create a direct connection between the abdominal cavity and the duodenal lumen by-passing the biliary duct's stump transected during surgery (4).

In conclusion, endoscopy can help to manage bile leaks after liver resections especially in case of severe leaks and concomitant septic complications in order to improve clinical outcomes.

\section{Acknowledgments}

Funding: None.

Cite this article as: Mutignani M, Dioscoridi L. Can endoscopic therapy help surgeons to manage post-hepatectomy bile leaks? HepatoBiliary Surg Nutr 2021;10(3):416-417. doi: 10.21037/hbsn-2021-8

\section{Footnote}

Provenance and Peer Review: This article was commissioned by the editorial office of Hepatobiliary Surgery and Nutrition. The article did not undergo external peer review.

Conflicts of Interest: Both authors have completed the ICMJE uniform disclosure form (available at https://hbsn. amegroups.com/article/view/10.21037/hbsn-2021-8/coif). The authors have no conflicts of interest to declare.

Ethical Statement: The authors are accountable for all aspects of the work in ensuring that questions related to the accuracy or integrity of any part of the work are appropriately investigated and resolved.

Open Access Statement: This is an Open Access article distributed in accordance with the Creative Commons Attribution-NonCommercial-NoDerivs 4.0 International License (CC BY-NC-ND 4.0), which permits the noncommercial replication and distribution of the article with the strict proviso that no changes or edits are made and the original work is properly cited (including links to both the formal publication through the relevant DOI and the license). See: https://creativecommons.org/licenses/by-nc-nd/4.0/.

\section{References}

1. Spetzler VN, Schepers M, Pinnschmidt HO, et al. The incidence and severity of post-hepatectomy bile leaks is affected by surgical indications, preoperative chemotherapy, and surgical procedures. Hepatobiliary Surg Nutr 2019;8:101-10.

2. Mutignani M, Forti E, Larghi A, et al. Refractory Bergmann type A bile leak: the need to strike a balance. Endosc Int Open 2019;7:E264-7.

3. Mutignani M, Dioscoridi L, Dokas S, et al. Endoscopic multiple metal stenting for the treatment of enteral leaks near the biliary orifice: A novel effective rescue procedure. World J Gastrointest Endosc 2016;8:533-40.

4. Mutignani M, Forti E, Dokas S, et al. Endotherapy for bile leaks from isolated ducts after hepatic resection: A long awaited challenge. Dig Liver Dis 2017;49:893-7. 